\title{
UNA NOTA SOBRE LAS PURIFICACIONES EN EL DERECHO GRIEGO: LA LEX SACRA DE CIRENE Y LAS LEYES DE PLATÓN
}

\author{
David Hernández de la Fuente
}

UNED

RESUMEN: En esta contribución pretendemos mostrar un estudio de caso sobre la interacción entre derecho y religión en la Grecia antigua. Se propone un estudio del papel de las purificaciones religiosas (katharmoi) en la integración del individuo en la comunidad política y en la cohesión del colectivo. A modo de ejemplo, se comparan en este artículo la Lex sacra de Cirene (SEG ix 72) y los pasajes de las Leyes de Platón que hacen referencia a la purificación.

Palabras clave: derecho y sociedad en la Grecia antigua, religión y derecho en la Grecia antigua, purificaciones, Lex sacra de Cirene, Leyes de Platón.

ABSTRACT: In this contribution we try to show a case study on the interaction between Law and Religion in Ancient Greece. We put forward a study of the role of religious purifications (katharmoi) in the integration of the individual in the political community and the cohesion of the group. As an example, this article compares the Lex sacra of Cyrene (SEG ix 72) and some key passages of Plato's Laws referring to purification.

Keywords: law and society in Ancient Greece, religion and law in Ancient Greece, purifications, Lex sacra of Cyrene, Plato's Laws. 


\section{INTRODUCCIÓN}

I a intersección entre religión griega y derecho es un aspecto de gran L importancia para los estudios de historia jurídica, social y de las mentalidades en la Edad Antigua. Es este un asunto de especial relevancia en todo el proceso histórico de la Grecia antigua, que está presente desde época arcaica a época helenística. La religión, concretada en el ritual y regulada a través de leges sacrae, es un mecanismo clave para el funcionamiento del entramado social de la polis a lo largo de su devenir histórico. Cuestiones tan variopintas como el derecho político o el derecho de familia, como en el caso de la integración de un miembro externo a la comunidad política por prescripción oracular o en el de la incorporación de un individuo a la familia o clan por medio de la adopción, atestiguan la interdependencia del derecho antiguo con la ritualización propia del ámbito religioso. ${ }^{1}$

Podemos decir, a modo de introducción metodológica, que la ley sacra se define, stricto sensu, como aquella disposición legal que regula los aspectos generales, sobre todo formales, del culto religioso: la elección de los sacerdotes, la administración de los templos y de sus propiedades, la organización de festivales. También hay otros aspectos más particulares que son abordados por este tipo de leyes, como por ejemplo la regulación exhaustiva de la práctica ritual -cómo habían de llevarse a cabo ciertos cultos-, la forma del sacrificio, cómo vestirse para cada ocasión, etc. ${ }^{2}$ Sin embargo, la lex sacra es también susceptible de ser definida lato sensu como aquella disposición legal que regula, en general, la relación de la comunidad política con lo sagrado

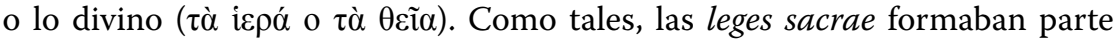
del conglomerado jurídico tradicional heredado en las diversas poleis griegas.

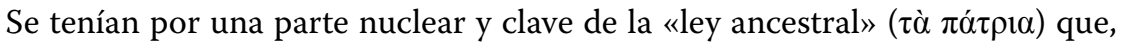
desde tiempo inmemorial, se resistía a ser codificada en forma escrita, incluso a partir del siglo vi a. C., cuando se consolidan las codificaciones en las diversas comunidades políticas griegas, precisamente porque eran percibidas como una legislación proveniente del mundo divino. Solo en determinadas ocasiones se puso esta ley por escrito en ciertas inscripciones como parte de aquel conglomerado en los llamados códigos que se han transmitido en ciertas inscripciones, ${ }^{3}$ algunas muy célebres, como la de Cirene o la de Gortina. Por

1. Para una reflexión de conjunto sobre este tema, que incluye un primer tratamiento de la presente cuestión, véase mi texto «Tres capítulos sobre derecho y religión en la Grecia antigua» en J. ALVARADo Planas, D. Hernández de la Fuente, R. López Melero, A. Rodríguez González, Nomos ágraphos, Nomos éngraphos. Estudios de derecho griego y romano. Dykinson, Madrid 2015, pp. 49-79.

2. Cf. Soкоlowsкi, F.: Lois sacrées des cités grecques. École française d'Athènes. Travaux et mémoires des anciens... E. de Boccard, París, (Supplement), 1969; PARKER, R.: «Law and Religion», en M. Gagarin y D. Cohen (ed.): The Cambridge Companion to Ancient Greek Law, Cambridge University Press, Cambridge, 2005, pp. 61-81.

3. Lupu, E.: Greek Sacred Law. A Collection of New Documents, Religions in the Graeco-Roman World, 152, Brill, Leiden, 2005, pp. 4-5. 
otra parte, los críticos han diferenciado tradicionalmente la ley sagrada ${ }^{4} \mathrm{de}$ otro tipo de actos de raigambre religiosa -especialmente los juramentos, las expresiones de magia y la maldición- que eran jurídicamente relevantes y cruciales, en el caso del juramento por lo sagrado, en los procedimientos judiciales en la antigua Grecia. La cuestión de la relación de la ley sagrada y la ley general es, claramente, un aspecto fundamental para la comprensión de las implicaciones sociales y políticas de la religión griega.

En esta breve contribución presentamos un caso que se refiere a las purificaciones religiosas y a su papel en la integración del individuo en la comunidad y en la cohesión del colectivo. Diversos pueblos han adoptado la práctica de la pureza ritual para evitar una serie de tabúes y contaminaciones que pueden comportar desgracias no solo religiosas sino también sociopolíticas. La religión incide así directamente en la comunidad política, pues como dice Burkert, «la purificación es un proceso social. Pertenecer a cierto grupo es conformarse a su estándar de pureza; el réprobo, el marginado y el rebelde son impuros». ${ }^{5}$ Los rituales de purificación están relacionados con la convivencia de lo cívico y lo sagrado, ya sea en toda forma de iniciación o ya también como mecanismo religioso en momentos de crisis global y culpa extendida al colectivo, en casos de epidemia, por ejemplo.

\section{SOBRE LAS PURIFICACIONES}

En la antigua Grecia, el modo más usual de purificar (kathairein, apolymaínesthai) ritualmente era rociarse o lavarse con agua y vestir ropas limpias: ya aparece en el primer canto de la Ilíada (I, 314-5) cuando el Atrida «ordenó que los hombres se purificaran (apolymaínesthai) y ellos se purificaron y echaron al mar las impurezas (lymata)». Otros elementos rituales son el fuego destructor, el liknon o cesta para aventar el trigo, la cebolla y, paradójicamente, también la sangre: "y sacrificaron en honor de Apolo cumplidas hecatombes de toros y de cabras junto a la ribera del proceloso mar. Y la grasa ascendió al cielo enroscándose en el humo», continua diciendo el texto de Homero (316-7). Había sacerdotes especializados (kathartai) que aparecen también en casos de epidemia o discordia civil para purificar la ciudad. El caso más representativo en la leyenda es el de Epiménides de Creta, que purifica Atenas de la discordia de Cilón. En su caso, es la sangre de unas víctimas purificadoras, unas ovejas, la que sirve para purificar la ciudad del crimen de sangre que empañaba la ciudad desde los tiempos de Megacles. ${ }^{6}$

4. HEILIGES RECHT, según el término acuñado por LATTE.

5. Burkert, W.: Greek religion. Archaic and classical, Oxford University Press, Oxford, 1985, pp. 75-76.

6. Sobre el episodio de Megacles y Cilón, $c f$. BARCELó, P.: Basileia, Monarchia, Tyrannis. Untersuchungen $z u$ Entwicklung und Beurteilung von Alleinherrschaft im vorhellenistischen Griechenland, HistoriaEinzelschriften 79, Stuttgart, 1993, pp. 120-125. 


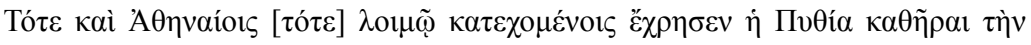

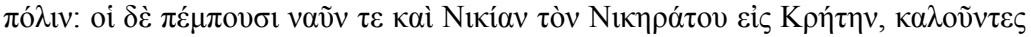

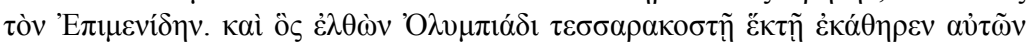

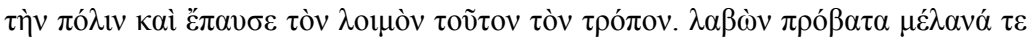

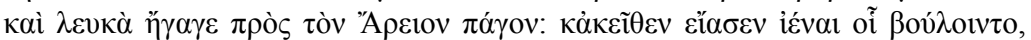

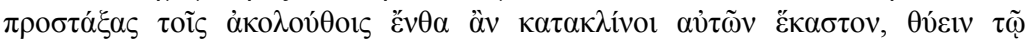

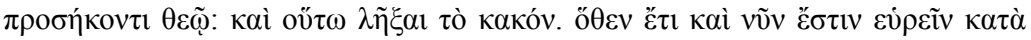

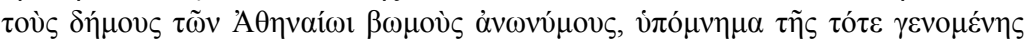
$\dot{\varepsilon} \xi 1 \lambda \alpha \dot{\sigma} \sigma \varepsilon \omega \varsigma$.

Por entonces la Pitia ordenó a los atenienses, que estaban atacados por la peste, purificar la ciudad. Ellos enviaron una nave capitaneada por Nicias, el hijo de Nicerato, a Creta para llamar a Epiménides. Y él acudió y purificó la ciudad en la Olimpiada cuarenta y seis, e hizo cesar la peste del modo siguiente: tomando unas ovejas negras y blancas las condujo a la colina de Ares. Y desde allí las dejó triscar por donde querían, tras dar orden a los servidores de señalar allí donde descansara cada una, para sacrificar a la divinidad conveniente. Y así hizo cesar el mal. Por eso aún ahora es posible encontrar en diferentes demos del Ática altares anónimos como reliquia de aquella purificación. ${ }^{7}$

Las purificaciones (katharmoi) pueden ser públicas, a través de expiaciones como las mencionadas, o privadas, en las abluciones rituales necesarias para aplacar al dios de la profecía, el gran Apolo. Se aplicaban a casos de miasma o polución, procedentes, principalmente, de la muerte, el nacimiento o el comercio sexual. ${ }^{8}$ Un ejemplo histórico muy conocido de cómo el recinto o espacio sagrado (témenos) de un templo ha de permanecer limpio de la mancha que suponen los alumbramientos o los cadáveres es la limpieza ritual que tuvo lugar en la isla de Delos. En un primer momento, la llevaron a cabo los atenienses bajo la tiranía de Pisístrato (c. 540 a. C.) retirando todas las sepulturas del recinto consagrado a Apolo que había en la isla. En previsión acaso de la gran relevancia política posterior de la isla, designada hogar y sede de la llamada Liga Delia, el dominio jurídico-religioso ateniense se consagró de nuevo desde el invierno de $426 / 5$ a. C. con otra purificación de la isla, la retirada de las sepulturas y la prohibición por decreto que nadie naciese o fuese enterrado allí. Esta vez, y en este caso de Delos, se consideró que toda la isla debía ser purificada como si toda ella fuera entendida como santuario de Apolo, dios de las purificaciones. El pasaje de Tucídides lo resume así: ${ }^{9}$

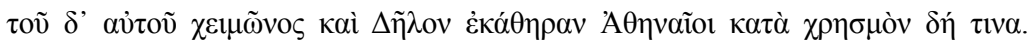

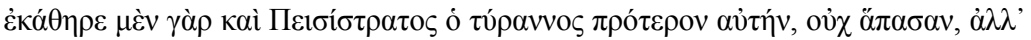
őбov àं

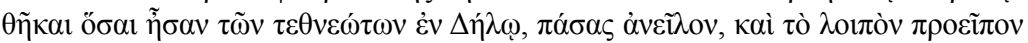

7. Diógenes Laercio, Vidas de filósofos ilustres I 110, trad. C. García Gual.

8. En general, $c f$. PARKer, R.: Miasma: Pollution and Purification in Early Greek Religion. Clarendon Press, Oxford, 1983.

9. Cf. también Tuc. I 8 1. Diodoro de Sicilia, XII 58. 


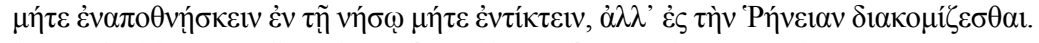

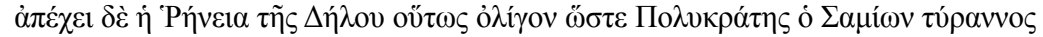

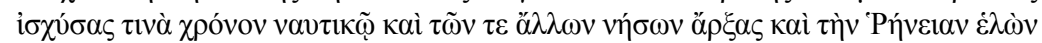

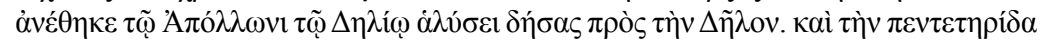

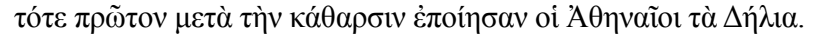

Todavía en ese mismo invierno, los atenienses purificaron Delos, de acuerdo con cierto oráculo. Con anterioridad ya había efectuado una purificación Pisístrato, el tirano, pero no en toda la isla, sino tan solo en la parte visible desde el santuario. Ahora, en cambio, Delos fue purificada totalmente, del modo que sigue: cuantas tumbas había en Delos fueron trasladadas de allí, y para el futuro prohibieron que se muriera o se pariera en la isla, sino que se debían trasladar para ello a Renea. Renea dista tan poco de Delos que Polícrates, tirano de Samos, que durante algún tiempo ejerció el control del mar y gobernó sobre todas las islas, conquistó también Renea y la consagró a Apolo Delio enlazando ambas islas con una cadena. Fue ahora por primera vez cuando los atenienses, tras la purificación de Delos, celebraron las fiestas cuadrienales delias. ${ }^{10}$
\end{abstract}

Como se ve, la purificación tiene una dimensión política muy importante, tanto en el plano interno de la polis como en el ámbito de las relaciones entre ciudades-estado, alianzas basadas en un trasfondo religioso y justificaciones de intervenciones militares: una buena muestra son estos dos ejemplos de la política interna y externa de Atenas en los siglos vi y v a. C. ${ }^{11}$ Pero, en la vertiente más propiamente jurídica y en el reflejo social de la cohesión interna de la polis, la purificación se ocupa del problema central de derramamiento de sangre en el seno de la comunidad. Ahí se muestra su sentido sociopolítico, en la intersección de religión y derecho, al tratar con el homicidio y asesinato los puntos más conflictivos del crimen y la culpa religiosa y jurídica que conlleva.

Primeramente, en el nivel del mito, quizá el mejor ejemplo de las purificaciones bajo el signo del dios oracular Apolo se encuentre en la trilogía micénica de Esquilo, la Orestía: el héroe Orestes debe vengar a su padre Agamenón -asesinado por su madre Clitemnestra-, a instancias de Apolo e impulsado por la ley no escrita y previa en el mito al derecho griego que decreta el pago de sangre por sangre dentro del clan familiar. Habrá de matar así a su propia madre por decreto de Apolo. Pero luego, para purificarse ritualmente del horrendo matricidio, marchará al oráculo de Delfos: esta trilogía representa a Apolo en un estado intermedio entre el dios que exige el derramamiento de sangre humana y el dios que la aplaca mediante el ritual (más tarde, acaso como reconciliación con la comunidad, recibirá la purificación cívica del tribunal del Areópago, en Atenas).

10. Historia de la Guerra del Peloponeso III 104.1-2. Trad. A. GuZmán Guerra.

11. Sobre el último y las consideraciones religiosas, a menudo soslayadas, del conflicto, $c f$. Brock, R.: «Thucydides and the Athenian purification of Delos», Mnemosyne: A Journal of Classical Studies, 49 (1996) 3, pp. 321-327. 
En segundo lugar, tras el reflejo del mito en la literatura (en este caso en la tragedia ática), hay que decir que las purificaciones apolíneas tenían una concreción ritual en los festivales de katharmoi atestiguados por las fuentes históricas. Un ejemplo de la purificación y expiación a través de un pharmakós lo refiere Plutarco al explicar el origen de una de estas fiestas purificadoras del santuario de Delfos:

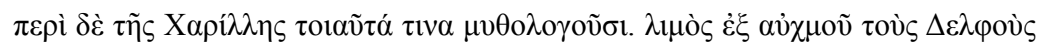

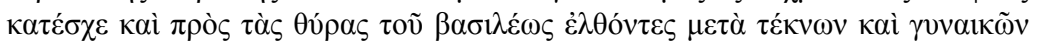

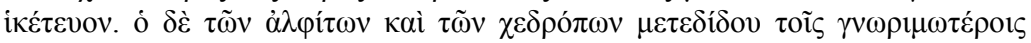

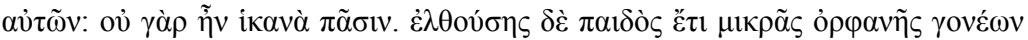

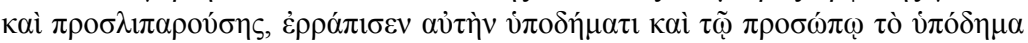

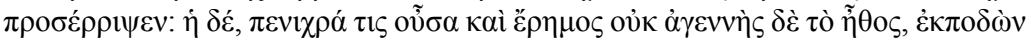

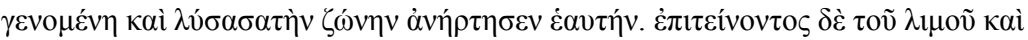

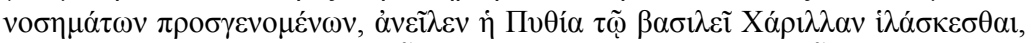

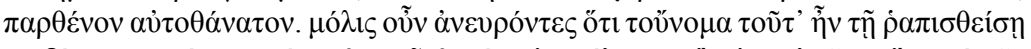

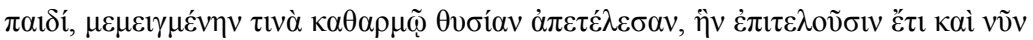

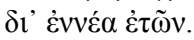

Acerca de Carila, se cuenta una historia que es como sigue. Los delfios estaban sufriendo una hambruna que vino después de una sequía. Llegaron a las puertas del palacio real con sus hijos y sus mujeres como suplicantes. Y el rey repartió entre ellos trigo y legumbres entre los más nobles de ellos, pues no había suficiente para todos. Y vino una niña aún muy pequeña, huérfana de padre y madre, y se postró como suplicante. Sin embargo, el rey le dio una patada y le arrojó su sandalia a la cara. Pero ella, aunque era pobre y solitaria, tenía un espíritu noble. Con que se marchó, desató su ceñidor y se ahorcó con él. A la hambruna se añadió entonces una peste y la Pitia dio un oráculo al rey diciéndole que debía aplacar a Carila, una muchacha que había muerto por su propia mano. A duras penas averiguaron que tal era el nombre de la niña que había sido golpeada. Así que llevaron a cabo un sacrificio que tenía en él algo de purificación, y esto se repite desde entonces cada nueve años. ${ }^{12}$

Lo que se repite -según esta explicación etiológica de la fiesta religiosa de Carila- era un ritual presidido por un rey (o un magistrado que hacía sus veces) ante las primicias de la cosecha, que distribuía por igual entre ricos y pobres, extranjeros y locales. Luego se traía una imagen de una niña, Carila, que recibía sus golpes con una sandalia. Una procesión conducía la imagen a una caverna donde se la colgaba de una cuerda: obviamente se trata, pues, de un fingido sacrificio humano, a través de la figura de una persona que sirve de pharmakós o chivo expiatorio para purificar a la comunidad y protegerla. Como puede verse, el oráculo de Apolo tiene un papel religioso fundamental en lo que Dodds denominara el paso de la «cultura de la vergüenza» a la «cultura de la culpa»: las purificaciones rituales que vienen a sustituir a la retribución 
mediante derramamiento de sangre. ${ }^{13} \mathrm{Es}$, sin duda, la transición entre el mundo del rito y el del derecho en el mundo arcaico.

En tercer lugar, en la intersección de ambas esferas, religiosayjurídica, se sitúa el acto que «mancilla» por excelencia: el derramamiento de sangre humana. El acto de asesinar provoca una polución peculiar, opuesta al concepto de pureza griega, hagnos, que es casi una experiencia física, el agos. El asesino queda impregnado de ese tabú (enagés) ${ }^{14}$ y debe limpiarse con un sacrificio especial que, en su esencia, es un rito de paso con sus fases de segregación, liminalidad y agregación, tal y como lo estudió ya Jane Harrison en sus Prolegomena to Greek Religion, un libro añejo pero que aún contiene reflexiones de gran profundidad sobre estos temas desde la perspectiva antropológica clásica. En este caso, el asesino se ha puesto fuera de la comunidad y su reincorporación en un nuevo nivel es un cierto acto de iniciación o reintegración cívica mediante un ritual que repite de forma demostrativa y, por tanto, inofensiva el derramamiento de sangre.

Comoquiera que sea, las purificaciones no se dejan al arbitrio del individuo, sino que se regulan jurídicamente en detalle como un deber en los códigos de leyes sacras griegas: las regulaciones más usuales tienen como objetivo mantener la pureza en un témenos: es lógico que un lugar sacro, que ha de permanecer limpio de todo miasma procedente de la sangre, de la muerte o del nacimiento, esté sujeto a regulaciones estrictas sobre cómo se ha de acceder a él. ${ }^{15}$ Las más atestiguadas se refieren a requerimientos de pureza para acceder a los templos, que tienen que ver con la virginidad, abstinencia sexual, la menstruación, el parto reciente o algunos tabúes alimenticios. Otras incluso hacen alusión a la «pureza de pensamiento ${ }^{16}$ necesaria para ser hagnos y entrar en un témenos. Pero, más allá de sus consecuencias estrictamente religiosas, el concepto de la purificación ejercerá también una gran influencia sobre la vida ciudadana, reforzando en la polis un sentimiento de culpa e impureza que la necesidad de purificación intensifica y refuerza. ${ }^{17}$

A los efectos de constatar la importancia de la ley sagrada y la normatividad religiosa en la comunidad sociopolítica griega proponemos a continuación una lectura conjunta de un testimonio histórico de derecho sacro, el atestiguado en una inscripción de la ciudad de Cirene, y el uso de las purificaciones que se acredita en las Leyes de Platón, una compilación de carácter constitucional

13. Dodds, E. R.: The Greeks and the Irrational, University of California Press, 2004, 17 ss. Sus apreciaciones sobre el incremento de la creencia en las purificaciones a partir del siglo vi a. C. han sido muy matizadas por PARKER, 1983. En el mito griego hay varios ejemplos de purificaciones tras célebres parricidios, como el de Orestes, que dejaron una fuerte impronta en la tragedia ática: véase, por ejemplo, el caso de Alcmeón, asesino de su madre Erifila por una venganza, interpretado en García GuAL, C.: $L a$ venganza de Alcmeón. Un mito olvidado, Fondo de Cultura Económica, Madrid, 2014.

14. BURKERT, 1985, p. 81

15. Lupu, 2005, 14-15.

16. Sokоlowski, 1962, n. 82. Sobre la virginidad griega, cf. SisSA, G.: Greek Virginity, Harvard University Press, Harvard 1990. Para PARKer, 1983, 96, las ofensas sexuales entran en la categoría de "contaminación moral metafórica».

17. Nilsson, M. P.: A History of Greek Religion, New York, 1964, p. 42. 
que proyectó el filósofo ateniense para una polis ideal, la ciudad cretense de Magnesia. Aunque en ambos casos se constata como punto de partida la importancia de la tradición religiosa, con el recurso al Apolo de Delfos, queremos preguntaros ahora en qué medida estas reglas y este uso de la función sacerdotal se enmarcan en las aspiraciones de las leyes reales o utópicas de ejercer un control social efectivo mediante lo que Amar (1972) ha llamado «exclusión ritual», con el fin último de regular la convivencia política en el proyecto platónico. En coincidencia con la tradición religiosa, en este diálogo de Platón el miasma es contagioso y conlleva la exclusión de contactos sociales y específicamente de contactos con miembros de la familia y de la ciudad en ámbitos de importancia para la cohesión religiosa y social de la polis, como las comidas en común o incluso la presencia simultanea en el agora, juegos o ta alla hiera (868 b1) a la vez que el hombre impuro. Incluso puede llevar al exilio temporal como en 864 e y 866 b o a la prohibición de entierro en el país (854 b ss).$^{18}$ En definitiva, si nuestra hipótesis es correcta, la purificación se configura como un excelente ejemplo de la manera en que Platón en las Leyes somete ciertos aspectos de este ritual al dios de Delfos. La comparación con la ley catártica de Cirene, que se presenta a sí misma como una respuesta oracular de Apolo, puede ser muy esclarecedora a ese respecto.

\section{La LeX SaCRa de Cirene y las Leyes de Platón}

La ley sacra de Cirene, que data del siglo IV a. C., ${ }^{19}$ contiene una importante sección final sobre purificaciones (líneas 11042 ) en el contexto de varios ritos de Apolo, Ártemis y algunas deidades agrarias, por una parte, y de reglas generales, sobre el diezmo y el matrimonio, por otra. Descubierta en 1922 en los baños romanos de Cirene, y concretamente como asiento del frigidarium, la ley fue publicada por vez primera por S. Ferri en 1927, y luego fue estudiada por Luzzato en $1936 .{ }^{20}$ Fue estudiada concienzudamente, como uno de los ejemplos clave de los katharmoi griegos, por Parker 1983 (apéndice 1). La ley ocupa una cara y dos tercios de otra en la estela, que comparte con una larga lista de ciudades que reciben grano durante la hambruna del 330 al 325 a. C. En ese sentido, puede existir una relación entre este suceso y la ley, que podría ser una reacción a la hambruna, si seguimos la opinión de Ferri, que data la ley 20 años después de aquella. Es interesante que, al comienzo de la columna A (1-3), la ley se presenta como respuesta del Apolo pítico, en lo que supone un caso único, pues es la primera ley sagrada sobre purificaciones que remite a Delfos.

\footnotetext{
18. Amar, M. A.: Collective religion in Plato's Laws. Ph. D. Princeton University, 1972, p. 219.

19. Inscr. SEG, ix 72, Rhodes, P. J. y Osborne, R.: Greek Historical Inscriptions 404-323 BC., Oxford University Press, Oxford, 2003, 494 ss.

20. Ferri, S.: La «Lex Cathartica» di Cirene, Alfieri, Milano, 1927, pp. 93-145; LuzzATo, G. L.: La «Lex cathartica» di Cirene, A. Giuffrè, Milán, 1936.
} 


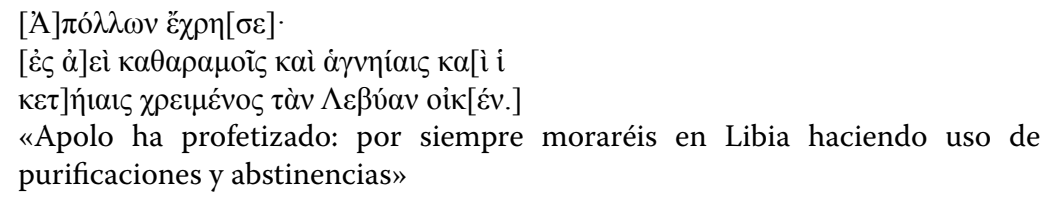

A lo que parece, los cireneos buscaron la aprobación de Apolo para su ley catártica, aunque puede que esto haga referencia a la tradicional veneración a este dios en la ciudad como responsable de su fundación como una colonia doria de Tera. No en vano, según refieren Heródoto (IV 150-8 y 161.1) y Diodoro (VIII 30), los habitantes de Cirene siguieron las instrucciones del oráculo de Delfos para instalarse en la ciudad, al preguntarte al dios «de qué manera nos estableceríamos mejor para vivir». Seguramente, y como veremos en la propuesta de Platón en las Leyes, se trata de un refrendo oracular a una legislación catártica ya redactada, más que de una ley dictada por el dios de Delfos al modo de la Rhetra espartana. ${ }^{21} \mathrm{Y}$ ello porque, a juzgar por la poca sistematización del código y por las alusiones a miasmas ya conocidos (B25), las leyes son de diversas fechas, sin que sea este texto una transcripción literal de un código de leyes arcaico. Además del mencionado papel de Apolo, los ritos de Ártemis previos al matrimonio de las jóvenes que se contienen en esta inscripción sugieren también una comparación con las Leyes de Platón, pues su regulación del matrimonio en tres fases (774 e-775 a), entre los 16 y 20 años (785 b), es susceptible de comparación con las tres fases del ritual de Ártemis en la inscripción de Cirene.

Entrando ya en el tema del miasma y la purificación que conciernen a Apolo, la primera disposición es una ley general contra el mal, la muerte y la enfermedad:

4-7 «Si la enfermedad, [la peste] o la muerte llegara contra el campo o la ciudad, sacrificad en frente de las puertas [en frente del] altar de la aversión a Apolo el que aleja el mal un cabritillo rojo».22

La comparación de esta ley catártica con varios lugares de las Leyes de Platón donde se alude a la purificación por medio del oráculo (866 a y 933 d) parte de la nueva lectura de este código legal que ha publicado recientemente N. Robertson $(2010,272-374) .{ }^{23}$ Se puede comparar este ritual de purificación de la muerte, por ejemplo, con el pasaje de las Leyes platónicas acerca de los saqueadores de templos (853 d-856 a): han de ser purificados en el templo del

21. Parke, H. R. W. History of the Delphic Oracle, Oxford, 1939, anexo 2, 332-334.

22. Sobre el significado del color rojo en el culto antiguo, $c f$. WUNDERLICH, E.: Die Bedeutung der roten Farbe im Kultus der Griechen und Römer, Topelmann, Giessen, 1925, 66-72.

23. Robertson, N.: Religion and Reconciliation in Greek Cities. The Sacred Laws of Selinus and Cyrene, Oxford University Press, Oxford, Nueva York, 2010. 
dios apotropaico, presumiblemente de Apolo. El estudio de las leyes sagradas de esta ciudad doria de espíritu conservador y apegada a sus ritos a la luz de la propuesta platónica para la ciudad ideal de Magnesia puede arrojar luz, por un lado, sobre el papel de la religión en las Leyes y, por otro, sobre el grado de dependencia de la obra platónica con su contexto legislativo y político.

Pero interesan más a nuestro propósito las líneas 50-55, sobre purificación de suplicantes, que en realidad se corresponden con tres tipos de rituales muy diferentes: 1) el primero es un rito de purificación de una casa afectada por «conjuros mágicos» de un enemigo. Aunque hay interesantes paralelos con la regulación platónica de la goeteia o magia negra, no entraremos en este tema, que dejaremos para otro lugar. En Leyes 908 d encontramos una valoración negativa de los que ejercen la magia y la fabricación de venenos, casos en los que se pone a prueba la entereza de los sacerdotes y adivinos. En caso de que un adivino o un médico incurran en un uso ilegítimo de sus facultades para dañar, envenenar o embrujar a un tercero será condenado a la pena de muerte (Leyes 933 c-e). 2) la segunda purificación se refiere a la consulta del oráculo local de Apolo, dios patrón de Cirene que, como hemos visto, confirma toda esta legislación. 3) la tercera purificación se refiere al autophonos, u homicida de propia mano, figura típica de este tipo de rituales en la literatura, la mitología y las fuentes legales, y su rehabilitación y reintegración en la sociedad a través de un intercesor. Veamos ahora con algo más de detalle la segunda y tercera de estas purificaciones.

\section{Purificación mediante consulta oracular}

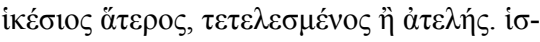

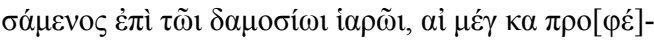

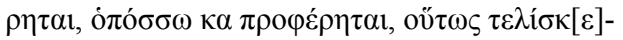

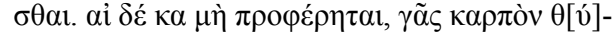

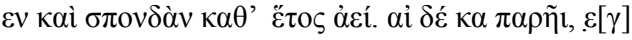

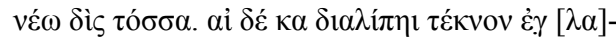

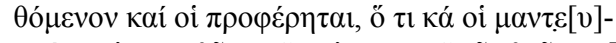

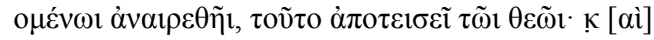

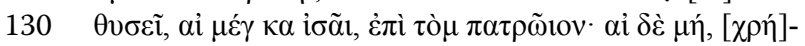
$\sigma \alpha \sigma \theta \alpha$.

122-131 «La segunda (purificación) de suplicante, pagada o no pagada. Tras sentarse sobre el altar público, si lo dispone el oráculo tanto cuanto ordene, así se pagará. Si no dispone nada, sacrifíquese el fruto de la tierra y hágase para siempre una libación anual. Pero si se omite esto, hágase dos veces tanto. Y si un niño descuida esto al no saber y se dispone algo para él, hágase lo que se disponga tras consultar al oráculo, y esto pagará al dios, y sacrificará, si sabe donde está, en la tumba de sus antepasados. Y si no que pregunte al oráculo». 
Este tipo de purificación tiene, como se ve, un importante trasfondo délfico que se constatará también en la constitución platónica. Puede que el oráculo ordene un sacrificio con cierta cantidad o valor: en caso de que no sea así simplemente hay que hacer una ofrenda agrícola y una libación. Se trata de una obligación hereditaria, que obliga incluso a los niños que no la conocen, por lo que, si se descuida la obligación, se proporciona una manera de arreglar el problema jurídico-religioso.

En comparación, cabe recordar que en las Leyes de Platón el oráculo determina todas las regulaciones concernientes a los sacrificios y las purificaciones: «Es necesario proveerse en Delfos de leyes acerca de todo lo

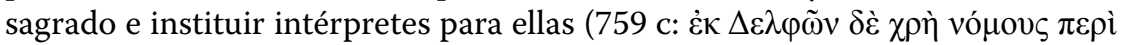

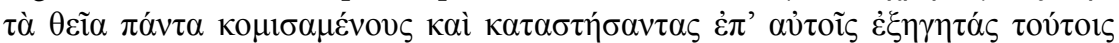
$\chi \rho \tilde{\eta} \sigma \theta \alpha \imath)_{»}$. La consulta sobre leyes sacras se lleva a cabo por mediación de los intérpretes, figura compleja y discutida ${ }^{24}$ que tiene una intrincada manera de elección en la que también participa el oráculo.

No en vano, estos intérpretes (exegetai) lo serán también, entre otras cosas, de las consultas a oráculos. Se trata, por lo demás, de unos magistrados con tradición en la mántica política «elegidos por Apolo de nueve candidatos seleccionados por el gobierno de la ciudad entre doce candidatos nominados por tres asambleas locales». ${ }^{25}$ También se ocupan de los dioses de cada tribu, de los festivales y de «fijar qué sacrificios y a qué divinidades será conveniente llevar a cabo para el Estado» (828). El oráculo -a veces Delfos o a veces simplemente los adivinos que lo consultan- tiene en las Leyes autoridad para determinar los cambios o novedades en asuntos religiosos, tanto en lo que

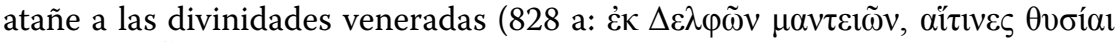

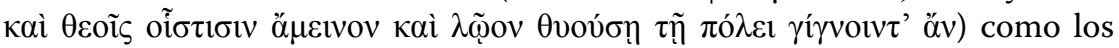
adivinos e intérpretes religiosos en lo que se refiere a estos temas, en los que

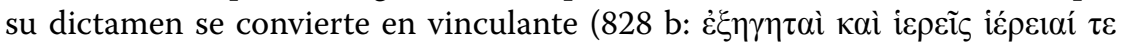

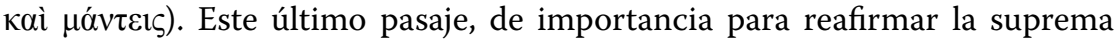
instancia de derecho religioso, establece el culto a los doce dioses del Olimpo y al ordenamiento de la religión cívica, cuya máxima autoridad en cuestiones de derecho sacro está en el oráculo apolíneo.

En definitiva, la experta guía en asuntos de purificación parece que se proporciona en las Leyes por parte de estos exegetas o intérpretes. Son de importancia y dignidad especial, como pone de manifiesto su compleja elección, y tenemos evidencia literaria y epigráfica de que este título existió en Atenas en el siglo IV a. C., pero no anteriormente. ${ }^{26}$ En paralelo a la institución platónica de estos exegetas se puede citar a los pythioi en Esparta, cuyo nombre

24. Cf. Hammond, N. G. L.: «The Exegetai in Plato's Laws», The Classical Quarterly, 2.1 (2), 1952, pp. 4-12 y Morrow, G. R.: Plato's Cretan City: a Historical Interpretation of the Laws, Princeton University Press, Princeton, 1960, pp. 496-499.

25. Oliver, J.: «On the Exegetes and the Mantic or Manic Chresmologians», American Journal of Philology, 73 (1952), p. 413

26. Morrow, 1960 , pp. 419-420. 
indica conexión con Delfos (según un testimonio de Heródoto VI, 57), de los que sabemos muy poco. Cada uno de los dos reyes tenía derecho a nombrar a dos «pitios» que eran sus compañeros de tienda y tenían el privilegio de comer con ellos.

La conexión con la purificación queda clara si se repara en que una parte importante de las referencias a los exegetas, más que a su labor de intérpretes de oráculos, concierne a las purificaciones (katharmoi) por motivos varios. En palabras de Morrow (1960, 424 en mi traducción):

Esto es apropiado pues los ritos de purificación practicados en Grecia remontan sus orígenes casi universalmente a Apolo ( $c f .865$ b). La mayor parte de las formas de homicidio, incluso las que no conllevaban pena legal, se creía que traían contaminación sobre el que había derramado la sangre y sobre su familia, así como sobre el estado entero, una polución que solo se podía remediar mediante la purificación ceremonial.

En Cirene y en las Leyes, así, la mediación oracular -también por parte de los sacerdotes intérpretes de oráculos- es un mecanismo básico del proceso purificatorio del miasma.

\section{Purificación del asesino mediante estatus de suplicante y sacrificio}

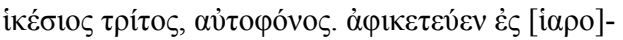

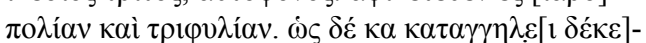

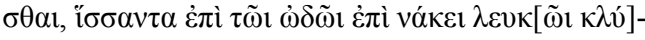

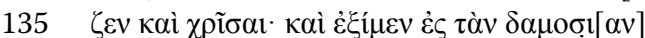

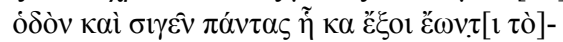

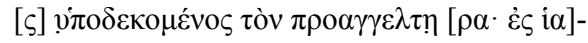

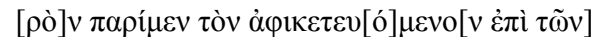

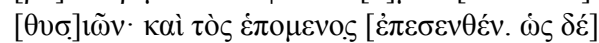

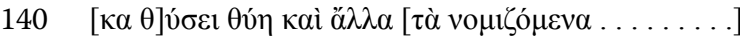

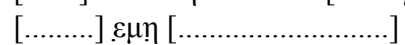

El tercer suplicante un asesino de propia mano (autophonos). Él lo presentará a la oficina [del sacerdote] y a tres tribus. Cuando él anuncie que ha llegado como suplicante, le sentará en el umbral sobre un vellocino blanco, le lavará y ungirá. Todos saldrán a la vía pública y guardarán silencio, y mientras ellos están fuera, los que respondan al anuncio. Ve [al santuario] objeto de intercesión para los sacrificios. Y los que le siguen. Cuando haya ofertado pasteles sagrados y las otras cosas usuales...

La tercera purificación de Cirene atañe a este tipo de asesino al que un intercesor reintegra en la comunidad, con la asistencia de un heraldo, un sacerdote y un grupo de testigos. El padrino sienta a la persona en el umbral del témenos con una piel de cordero blanco como vestimenta, lo lava y lo unge 
ante los testigos que simbolizan a la comunidad política y ante las autoridades religiosas. Luego se hace una ofrenda de un pastel sagrado y se sacrifica una víctima, seguramente oficiando el propio asesino.

En el caso del homicidio, que se recoge de esta manera en la ley de Cirene, conviene recordar que la purificación y el sacrificio en los testimonios de Atenas también van de la mano ( $c f$. Leyes 866 a). El suplicante tiene un auspiciador que le presenta como suplicante... quizá refugiado del extranjero. En tragedia la palabra autophonos y otras similares (autophontes, autóktonos, autosphagés ...) son normalmente referidas al que mata a los de su propia estirpe, como aparece también aquí, aunque suele tener el significado general de «homicida de propia mano» (Esquilo, Agamenón 1635). En las Leyes de Platón aparece, por ejemplo, autocheir (872 a) con ese sentido.

Hay otra comparación interesante con un ley funeraria de Ceos en la que se prescribe un procedimiento purificador para la casa y las personas que estén contaminadas por la muerte y para evitar que este miasma se extienda por la comunidad: el último párrafo se refiere a un homicida hikesios o suplicante. ${ }^{27}$ En todo caso, estas leyes contra el miasma contraído por asesinato evidencian un punto de encuentro clave entre el derecho y la tradición religiosa. Como ha notado Parker, 1983, 116, el ritual purificador en caso de asesinato en la ley sagrada supone casi una racionalización que conjura lo que en origen podía haber sido el miedo de la venganza por parte del clan.

En las Leyes Platón menciona las purificaciones por homicidio, ya sea cometido bajo la influencia de la locura (864 e), por accidente en los juegos o ejercicios militares (865 c-866 c), bajo influjo de la pasión (867 c-869 d) o también el asesinato premeditado $(871 \mathrm{a}-\mathrm{c})$. Precisan ser purificadas la casa donde un esclavo homicida ha sido acogido (916 c) e incluso la casa de un asesino que muere sin hijos, una purificación «según la ley» antes de que se le asigne a otra familia (877 e). En todos los casos, los exegetas tienen autoridad sobre los ritos de purificación y se recurre al oráculo para confirmarla. Los sacerdotes mánticos, como los exegetas, desempeñan un papel fundamental en esta purificación, así como para el orden social y el propio derecho penal de la ciudad ideal de las Leyes. Platón establece purificaciones y arbitrajes oraculares en caso de los crímenes contra el alma (865 a-874 d), especialmente el homicidio premeditado, el más terrible de los delitos junto con el saqueo de templos. Y ello no es extraño, pues la purificación de la comunidad de la mancha o miasma que produce el derramamiento de sangre es tradicionalmente atribuida al dios del oráculo, cuando no a este mismo, en la religión griega, como se constata desde el mito antes mencionado de Orestes.

La ley en Platón ha de amparar al vengador de un crimen de sangre, siempre de acuerdo con el procedimiento ritual de la purificación, mediante sacrificios a ciertos dioses, y debe tener en cuenta, a la vez, las necesarias plegarias preventivas para evitar el homicidio en la comunidad ( 871 b-d: «con

27. Lupu, 2005, p. 79. 
la ayuda de los intérpretes, los adivinos y del dios, los guardianes de la ley deben regular por medio de leyes cuáles son estos dioses y cuál la forma de tramitar estos juicios ante los tribunales que podría ser la más correcta desde

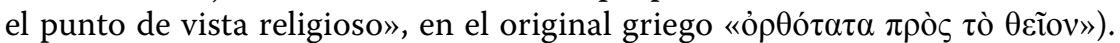
La pena de muerte para los homicidas, el castigo más grave en la ciudad de Magnesia, coincide no por casualidad con el castigo a los ladrones de templos (871 d), delito de impiedad máxima.

También en el caso de homicidio accidental, en otro supuesto de esta suerte de «código penal» platónico, el oráculo de Delfos es básico para regular la convivencia, como hemos estudiado ya en otro lugar:

«Si un hombre resulta muerto por un amigo o en unos juegos públicos -ya sea su muerte inmediata o a resultas de las heridas-, o si, por otro lado, fallece en la guerra o en alguna acción de entrenamiento para la guerra, ya sea practicando con la lanza sin armadura o en el transcurso de alguna maniobra con armamento pesado, en ese caso, cuando haya sido purificado según establece la prescripción de Delfos, se le tendrá por puro» (865).

Incluso la profesión del médico también precisa de la purificación délfica en

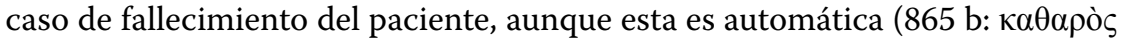

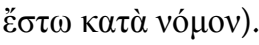

\section{A MODO DE CONCLUSIÓN}

En definitiva, el tratamiento jurídico de los ritos de purificación en la ciudad ideal de Platón parece fiel a la tradición helénica, y concretamente doria, que se atestigua en la ley sacra cirenaica y no parece expresar simbólicamente las propias ideas teológicas o filosóficas de Platón, ${ }^{28}$ aunque en absoluto sea contrario a ellas. En estos casos paralelos que se han comentado, el nomos ágraphos que supone la regulación de derecho sagrado de las purificaciones se pone por escrito en la inscripción comentada y, además, encuentra ecos filosóficos en el proyecto constitucional de Platón. Siguiendo a Amar (1972), podemos clasificar, finalmente, en siete puntos las coincidencias de la función catártica en Platón con las de la tradición religiosa (representada, en nuestro ejemplo, por la ley sacra de Cirene):

1. La necesidad sin excepción en caso de homicidio de pasar un rito purificatorio. ${ }^{29}$

2. El papel central del oráculo de Apolo en toda la esfera de la purificación. ${ }^{30}$ Todo un «trasfondo délfico» en Platón. ${ }^{31}$

28. AMAR, 1972, pp. 213 y ss.

29. Nilsson, M. P.: A History of Greek Religion, Nueva York, 1964, p. 196

30. NiLSSON, 1964, p. 195.

31. Reverdin, O.: La Religion de la Cité Platonicienne, E. de Boccard, París, 1945, p. 99. 
3. El tabú acentuado del homicidio en un clan (Leyes 868 c-871 c).

4. La noción de que el contacto entre espacio sagrado y homicidio es el sacrilegio más impío. ${ }^{32}$

5. La prohibición de que un homicida ejerza cualquier función sagrada.

6. La idea de que el miasma de un homicida es una polución contagiosa que contamina no solo a los miembros de la familia, sino a cualquiera que entre en contacto con él, como a la propia ciudad (Leyes $873 \mathrm{~b}$ ).

7. La práctica legal en los juicios de homicidio $(871 \mathrm{c}-\mathrm{d})$, que para Nilsson ${ }^{33}$ «guardan una cercana asociación con los ritos religiosos y pueden ser tan complicados que algunos expertos especiales (exegetai) pueden ser llamados para llevarlos a cabo adecuadamente».

Una coincidencia muy notable es la manera en que, tanto en el caso de las Leyes de Platón como en el de la ley sacra de Cirene, ciertos aspectos de la legislación catártica son sometidos al juicio del dios de Delfos, que es por excelencia la divinidad purificadora y mántica a la par. Sin embargo, la figura de los intérpretes representa la mediación entre la ley sacra y su uso platónico: Platón los usa para adecuar los dictados del oráculo al cuerpo legislativo y a la realidad política de la ciudad. Sospechamos por los testimonios literarios y epigráficos que existieron sacerdotes con semejantes funciones en la Atenas o Esparta históricas, aunque esto queda aún sub iudice. En ambos casos, lo que se le pide al dios del oráculo es que exponga el ritual, mientras que los aspectos más importantes del exilio, castigo y perdón los determinan el legislador cireneo o el propio Platón. ${ }^{34}$ Aunque la ley catártica de Cirene se presentase como una respuesta oracular de Apolo procedente de Delfos, hay acuerdo general en que las regulaciones reales, tanto por dialecto como por el contenido, fueron formuladas en la propia Cirene.

A modo de conclusión provisional, podemos confirmar que la institución de la purificación en el derecho griego contribuye a metas no estrictamente religiosas, además de sustituir la venganza de sangre y someter a los clanes a la influencia de la polis. Como se ve en el caso de la ciudad ideal de Magnesia, que sin duda refleja patrones de otras ciudades de ámbito legislativo dorio más allá de la comparación con Cirene, la purificación ritual contribuía a reforzar las formalidades religiosas entre los ciudadanos y dos importantes factores cívicos: el sentido de la culpa y el del deber. Dos aspectos clave en el nuevo orden que propone Platón en su último diálogo, una legislación exhaustiva de fuerte impronta prodoria, frente a la tradición democrática de Atenas y como último intento de reforma de una polis en tiempo de crisis.

32. NiLsson, 1964, pp. 43 y 196.

33. Ibidem.

34. PARKe, 1939, p. 140. 